Article

\title{
Aerodynamic Testing of Helicopter Side Intake Retrofit Modifications
}

\author{
Florian Knoth ${ }^{*}+$ and Christian Breitsamter ${ }^{\dagger}$ \\ Chair of Aerodynamics and Fluid Mechanics, Department of Mechanical Engineering, \\ Technical University of Munich, 85748 Garching bei München, Germany; christian.breitsamter@aer.mw.tum.de \\ * Correspondence: florian.knoth@aer.mw.tum.de; Tel.: +49-89-289-16439 \\ + These authors contributed equally to this work.
}

Academic Editor: Konstantinos Kontis

Received: 5 May 2017; Accepted: 19 June 2017; Published: 23 June 2017

\begin{abstract}
Aerodynamic characteristics of helicopter engine side air intakes are investigated. The experimental data set is obtained by wind tunnel testing of a full-scale helicopter fuselage section model. For the simulation of realistic engine operation, engine mass flow rates are reproduced. Five-hole pressure probe data of the aerodynamic interface plane as well as local surface pressure distributions are compared for different geometries and operation conditions. Previous investigations indicate that unshielded, sideways-facing air intakes yield lowest distortion and highest total pressure levels in low speed conditions. In fast forward flight condition, however, forward-facing intake shapes are more beneficial. On this basis, the current research assesses the optimization potential of retrofit modifications such as a rear spoiler (small scoop) and an intake guide vane. Two optimal configurations of retrofit modifications are identified, combining benefits of the various basic intake and plenum chamber shapes.
\end{abstract}

Keywords: experimental aerodynamics; helicopters; air intakes

\section{Introduction}

Helicopters play an essential role in air transport on the basis of their unique vertical take-off and landing (VTOL) abilities. Thus, in certain situations and applications such as search and rescue (SAR) missions, particularly lightweight helicopters prevail over fixed-wing aircraft. The reduction of emissions is a crucial aim. For this purpose, aerodynamic optimization of the fuselage shape is performed [1] as well as optimization of the engine installation [2]. One means is to enhance compressor inflow conditions. As reference plane for the evaluation of the inflow conditions, the aerodynamic interface plane (AIP) is applied. For this plane, evaluation parameters like a distortion parameter $D C_{60}$ [3] and total pressure ratio $\eta$ are investigated. In addition to emission reduction, stable engine operation is an essential aim. Unstable operation can occur if the compressor is subjected to complex intake flow conditions. These are quantified by temporal and spatial variations of total pressure as well as total temperature at the AIP. The application of intake test facilities allow for the evaluation of distortion and total pressure losses in an aircraft's early design phase. Especially, large scale testing can reduce development time and cost as well as lead to an increase in safety margins. If both the Reynolds and Mach number similarity is fulfilled, the effect of geometric variations and details, such as intake grids, are reproduced most realistically. Particularly Reference $[2,4,5]$ present a very thorough overview of the engine air intake research including several fixed-wing and rotorcraft configurations. Special operation requirements are imposed on helicopter intakes. As part of Reference [6], the interaction of the rotor with the intake flow field was investigated. To protect the engine in dusty and dirty environments, the effect of inlet barrier filters [7], engine inlet particle separators, such as scavengers [8] or foreign object damage grids, were investigated in detail. 
A study of a dynamic intake including an inertial separator was conducted as part of Reference [9]. In Reference [10] significant differences of pitot and sideways-facing intake shapes were presented. In Reference [11,12], ice accretion at flight-realistic Reynolds numbers and static temperatures was investigated both in full-scale intake-icing wind tunnel tests and numerical simulations.

Comprehensive aerodynamic investigations and optimization of engine air intakes are performed at the Chair of Aerodynamics and Fluid Mechanics of the Technical University of Munich (TUM-AER) for a light helicopter. For this purpose, a modular full-scale model of a helicopter fuselage section was designed.

Firstly, the experimental setup is described. Subsequently, retrofit aerodynamic modifications are presented that improve the characteristics of three basic intake shapes. Various operating conditions are applied with an emphasis on fast forward flight. Total pressure loss and total pressure distortion are investigated in the AIP using a circumferentially adjustable 5-hole pressure probing system. Further information about local flow phenomena is provided by static surface pressure distributions. As basis for the optimization, the aerodynamic characteristics of three basic intake variants have been investigated in previous research [13], a static side intake, a semi-dynamic side intake as well as a dynamic side intake including a scoop. Detailed numerical investigations have been performed for the static side intake in Reference [14] to give further insight into flow phenomena of such intakes. Diverse factors motivate the choice of plenum-chamber-type side intakes. Side intakes are applicable as particle separators and they can reduce additional drag of the engine-airframe integration. In case of the already existing helicopter configuration (Airbus Helicopters Bluecopter Demonstrator, [15]), a main requirement was the intake positioning aft of the rotor axis.

A general overview of the experimental results of the basic intake shapes as well as selected retrofit modifications was presented in Reference [16]. In the following, the influences of the retrofit modifications such as rear spoilers and an intake guide vane are specifically discussed. A parameter study is conducted to assess the effect of variations in rear spoiler heights, intake shielding or streamwise intake guide vane positioning. Optimal retrofit modifications are found which combine the different beneficial operation conditions of sideways-and forward-facing side intake configurations.

\section{Experimental Testing}

Experiments are performed in the Göttingen-type wind tunnel A of TUM-AER, see $[13,14,16]$. The measures of the wind tunnel test section are $1.8 \mathrm{~m} \times 2.4 \mathrm{~m} \times 4.8 \mathrm{~m}$ (height $\times$ width $\times$ length). In open test section operation, the maximum freestream velocity is $U_{\infty}=65 \mathrm{~m} / \mathrm{s}$. The turbulence intensity is below $0.4 \%$. The uncertainty in the mean velocity distribution in space and time is below $0.7 \%$. The uncertainty in freestream direction is under $0.2 \mathrm{deg}$ and static pressure variations are less than $0.4 \%$.

\subsection{Model Installation}

The wind tunnel model integration including subsystems and adjacent wind tunnel $(\mathrm{W} / \mathrm{T})$ components is depicted in Figure 1. All corresponding components are listed in Table 1.

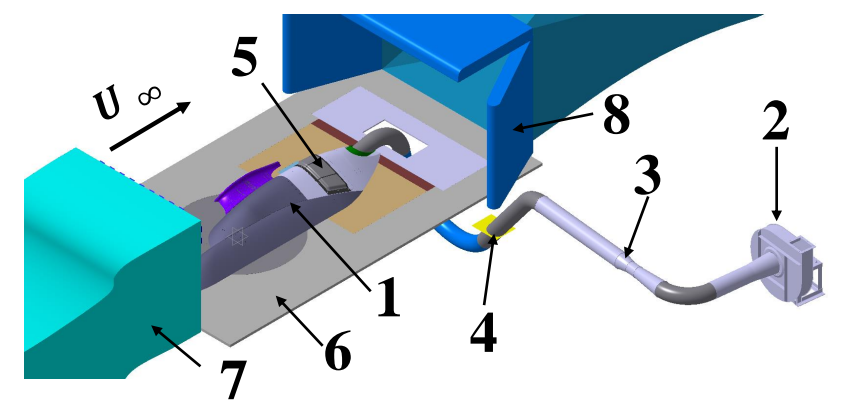

Figure 1. Overview of the $\mathrm{W} / \mathrm{T}$ setup. 
Table 1. Components of the $\mathrm{W} / \mathrm{T}$ setup.

\begin{tabular}{ll}
\hline $\mathbf{1}$ & Fuselage section wind tunnel model \\
$\mathbf{2}$ & Radial fan \\
$\mathbf{3}$ & Venturi meter \\
$\mathbf{4}$ & Duct system \\
$\mathbf{5}$ & Air intake section \\
$\mathbf{6}$ & W/T floor \\
$\mathbf{7}$ & W/T nozzle \\
$\mathbf{8}$ & W/T collector \\
\hline
\end{tabular}

Local Mach and Reynolds number similarities are fulfilled simultaneously by full-scale model testing. The W/T model's outer geometry represents a fuselage part model, see Figure 2a. The main rotor influence in fast forward flight is small for the portion of the fuselage where the intake section is situated, cf. [17]. For a reduction of measurement errors, the blockage in the test section is kept at a level of $7-8 \%$, as proposed in [18]. The result of the spatial restrictions due to test section dimensions is a truncated fuselage section, which is depicted in Figure 2a,b. The truncation of the fuselage led to a reduction of the longitudinal extent from $6 \mathrm{~m}$ to $4.5 \mathrm{~m}$ comparing the full fuselage and the truncated fuselage section.

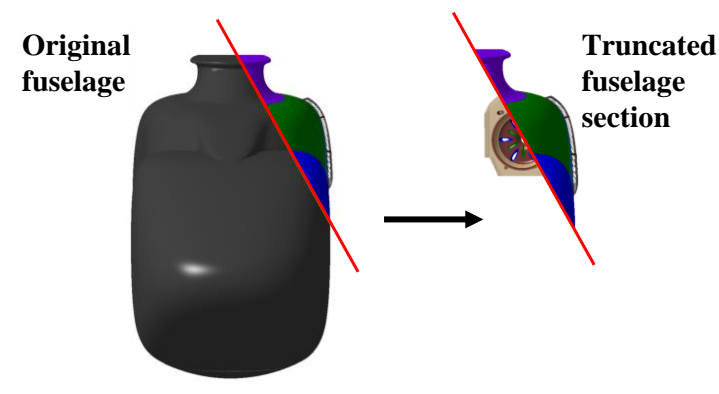

(a)

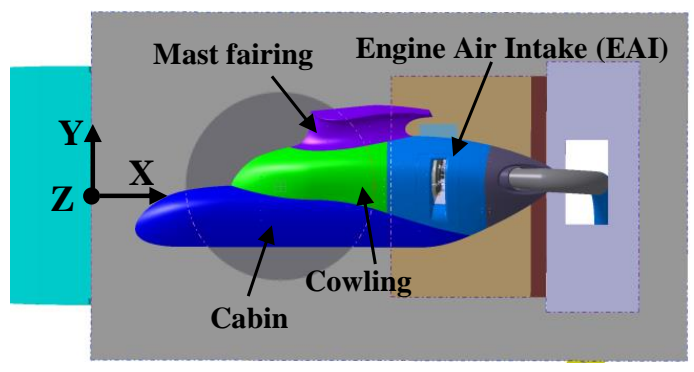

(b)

Figure 2. (a) Truncation of the fuselage in front view; (b) topview of outer W/T model components, positioned in test section.

In numerical simulations (cf. [14]), surface streamlines of a full fuselage and a sectional fuselage case were compared upstream of the air intake location. The difference in flow angles close to the front intake lip (Figure $2 \mathrm{~b}$ ) were below $\beta<2.3 \mathrm{deg}$, comparing both cases. The deviations of the AIP coefficients (cf. Equations (2) and (3)) were $\Delta \bar{\eta}_{\text {norm }} \approx-0.06 \%$ and $\Delta D C_{60} \approx 2.12 \%$. Therefore, for such configurations similar AIP characteristics originate from small deviations in flow angles relative to the front intake lip.

The geometry's inner components (Figure 3c) are connected to the engine air intake (Figure 3b). The inner components are the engine plenum chamber (EPC) and the engine intake duct (EID). The engine plenum chamber is attached to the engine air intake. It embeds the engine intake duct, which is a nozzle leading to the AIP. In contrast to the real helicopter, in the experiment, the circular 
duct is extruded in the direction of the engine's axis downstream of the AIP. Figure 4 presents in detail the components and their connection. To reproduce typical fast forward flight operation conditions (cf. [19]), angles of yaw between $-5 \mathrm{deg}<\beta<+5 \mathrm{deg}$ can be adjusted in the experiments. In the coordinate system of the real helicopter, the resulting angles of attack are $-4.4 \mathrm{deg}<\alpha_{H}<+4.4 \mathrm{deg}$ and the sideslip angles are $-2.4 \mathrm{deg}<\beta_{H}<+2.4 \mathrm{deg}$.

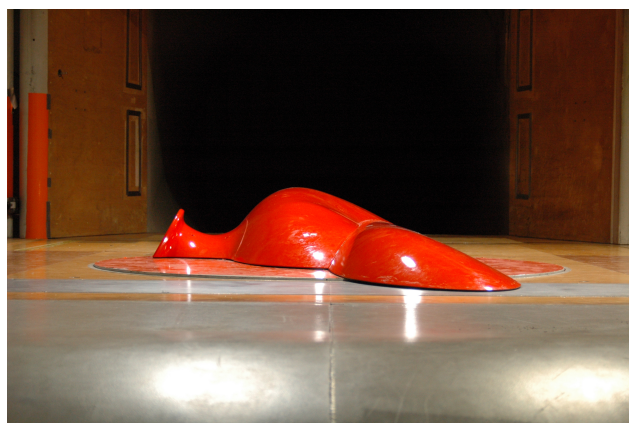

(a)

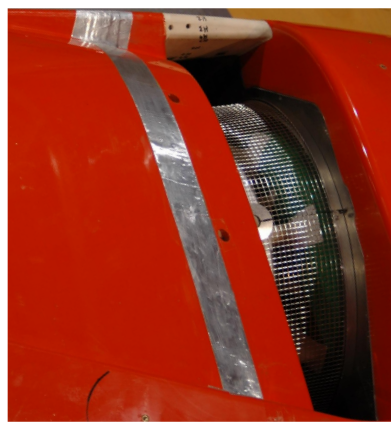

(b)

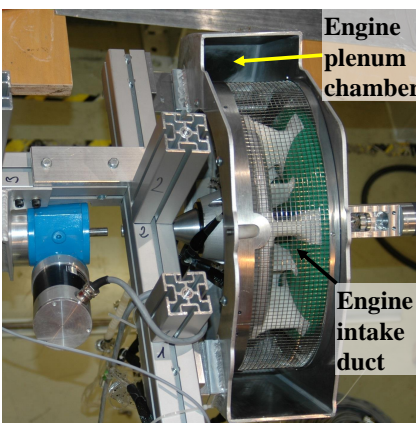

(c)

Figure 3. (a) $\mathrm{W} / \mathrm{T}$ fuselage section in front view; (b) intake 2 in perspective view; (c) detail view of integration of the $\mathrm{W} / \mathrm{T}$ model's inner components.

\subsection{Geometric Variations}

Figure 5 gives an overview of the intake geometries tested in the $\mathrm{W} / \mathrm{T}$ campaigns. The basic variants are combinations of three intakes and three plenum chambers, cf. [13]. The basic geometries and their characteristics are only briefly summarized, whereas the retrofit modifications and their geometric parameters are presented in more detail.

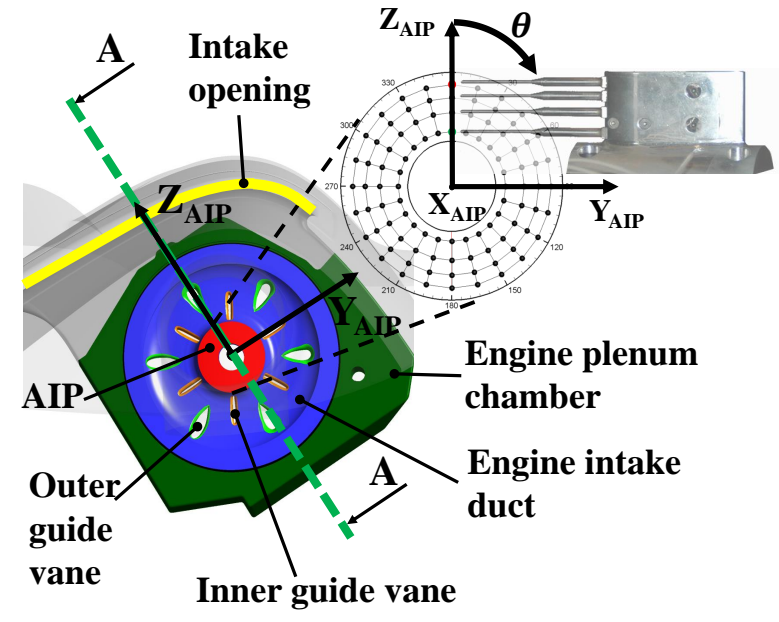

(a)

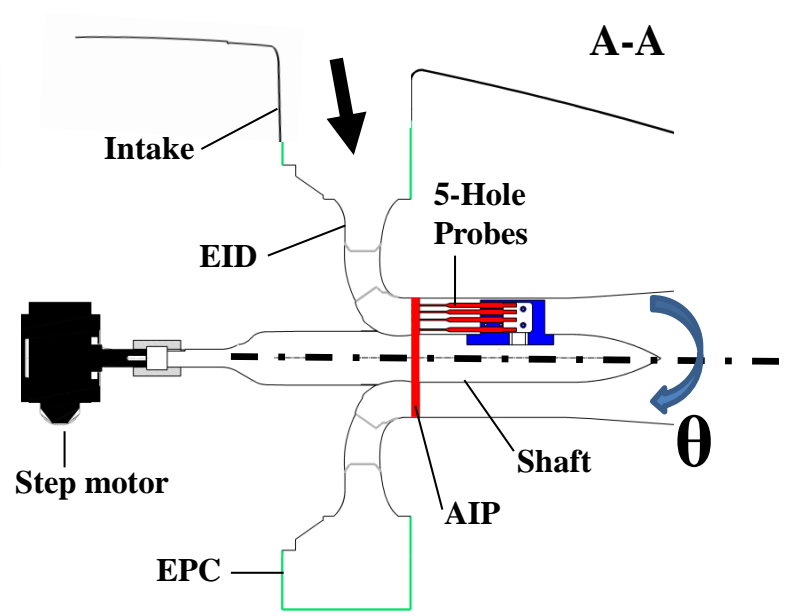

(b)

Figure 4. (a) Upstream view in $Y_{A I P}-Z_{A I P}$ plane, scheme of 5-hole-probe AIP measurement locations; (b) cut view $\mathrm{A}-\mathrm{A}$ in $X_{A I P}-Z_{A I P}$ plane, inner components and 5-hole probe adjustment. 


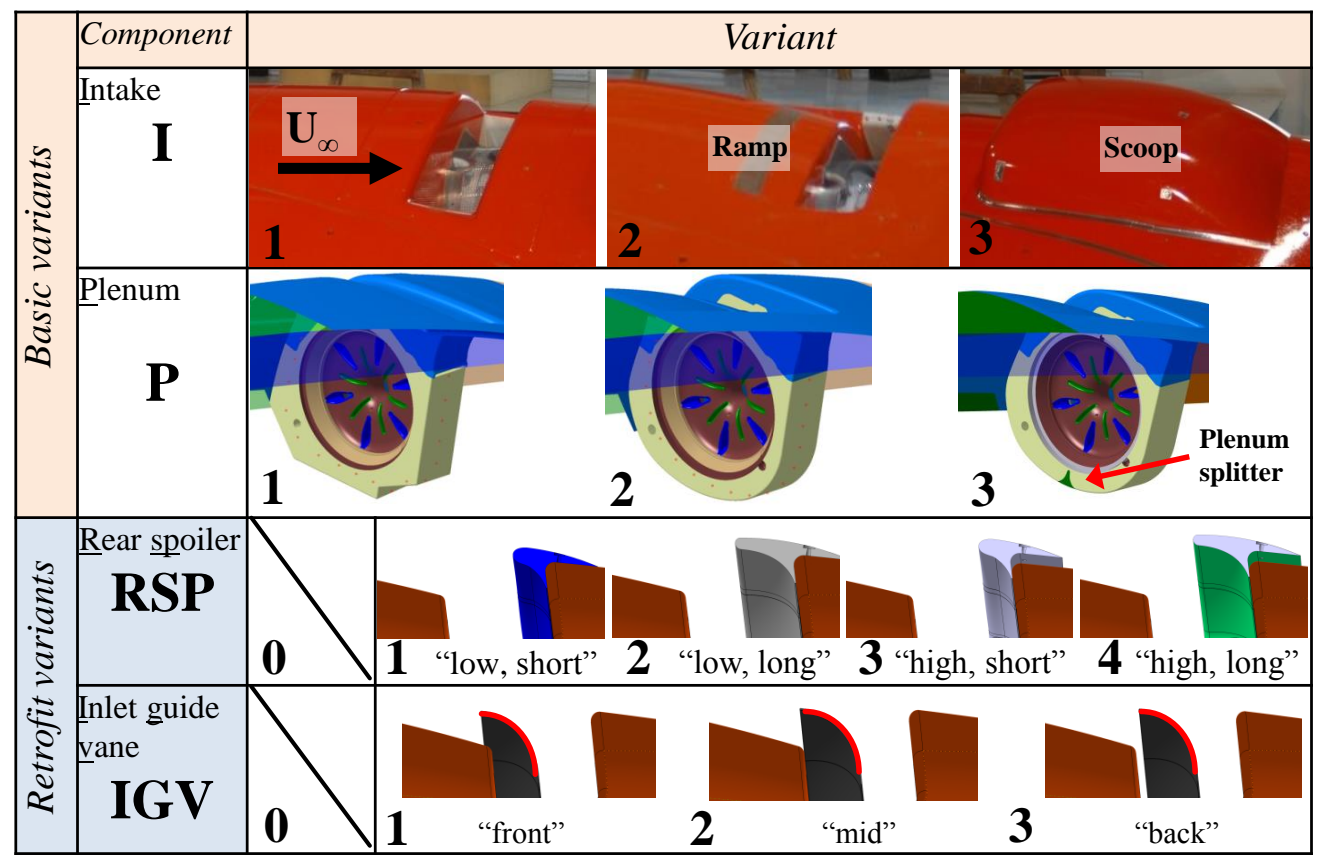

Figure 5. Overview of geometric variations.

Intake Variant 1 was developed as a static side intake. The intake Variant 2 was designed as a semi-dynamic side intake incorporating a ramp to improve recovery of dynamic pressure upstream of the intake opening. Intake Variant 3 is based on Variant 2 but features an additional scoop. Furthermore, three basic engine plenum chamber versions were tested. The plenum Variant 1 features a square-edged shape whereas the second variant is of an overall rounded shape. By adding a plenum splitter to Version 2, a third plenum version was created, cf. Figure 6a. The splitter's main aim is to guide the air flow and deflect it from a circumferential to a radial direction. Different positions and heights were tested. The most effective plenum splitter featuring the highest total pressures in the AIP is considered in the present work.

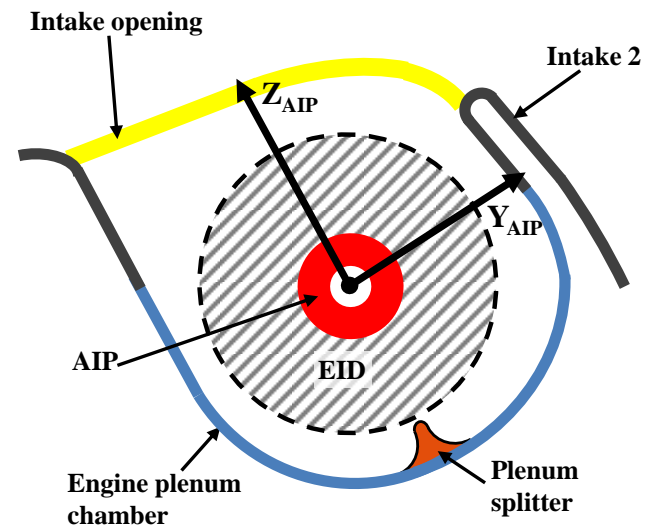

(a)

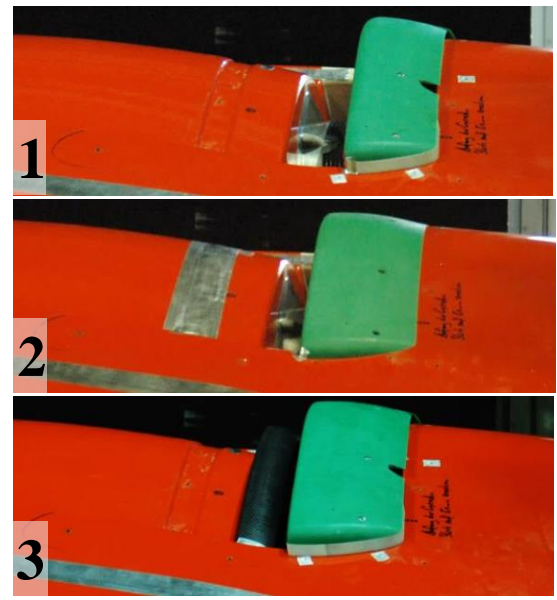

(b)

Figure 6. Overview of retrofit modifications. (a) Schematic cut view of Intake 2 in upstream perspective, inner components: EPC, EID, AIP and plenum splitter; (b) Retrofit modifications examples: (1) high and short rear spoiler, (2) low and long rear spoiler, (3) high and long rear spoiler, front intake guide vane. 
The evaluation of the results of the $\mathrm{W} / \mathrm{T}$ measurement and analysis indicated that each of the intake Variants 2 and 3 have a benefit compared to Intake 1 at different operation points. Thus, a mixture of both configurations is desired that covers all helicopter operation points. For this purpose, further retrofit variants, namely a rear spoiler (small scoop), an intake guide vane and combinations of both are investigated. Four different rear spoilers are tested in combination with the combination of Intake 2 and Plenum 3 to assess the best combination of height and length of the rear spoiler, as shown in Figures $6 \mathrm{~b}$ and 7 . The intake overlapping ratio $R=l_{R S P} / l_{I}$ describes the relative overlapping of the intake opening (axial extent $l_{I}$ ) due to the rear spoiler length $l_{R S P}$. Furthermore, a relative height parameter $H_{r e l}=h_{R S P} / h_{I 2}$ is defined as the ratio of the rear spoiler height $h_{R S P}$ measured from the front intake lip and the Intake 2's height of the back intake lip relative to the front intake lip.

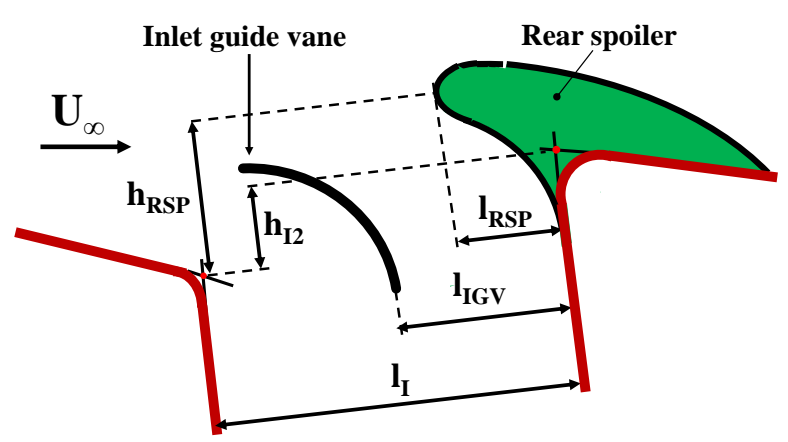

Figure 7. Schematic display of retrofit modifications and parametrization.

The rear spoilers are meant to increase the static pressure upstream of the intake opening (ram effect). The purpose of the intake guide vane is to support the deflection of the ingested air around the front intake lip (see Figures $6 \mathrm{~b}$ and 7 ) for a reduction of separated flow regimes directly downstream of the intake lip as achieved in [20]. The intake guide vane's relative position $P_{I G V}=\left(1-l_{I G V}\right) / l_{I}$ is defined by the relation of its trailing-edge position from the back intake lip $l_{I G V}$ relative to the overall axial extent $l_{I}$ of the intake opening. All parameter values are given in Table 2 . In the following, the basis for the optimization, namely the Intake 2 and Plenum 3 combination, is denoted as "baseline".

Table 2. Rear spoiler parameter values and intake guide vane positioning.

\begin{tabular}{lccc}
\hline Retrofit & \multicolumn{3}{c}{ Parameter } \\
\cline { 2 - 4 } Variant & $\boldsymbol{R}$ & $\boldsymbol{H}_{\text {rel }}$ & $\boldsymbol{P}_{I G V}$ \\
\hline RSP 1 & 0.29 & 1.47 & - \\
RSP 2 & 0.5 & 1.75 & - \\
RSP 3 & 0.29 & 1.91 & - \\
RSP 4 & 0.5 & 2.19 & - \\
IGV 1 & - & - & 0.43 \\
IGV 2 & - & - & 0.5 \\
IGV 3 & - & - & 0.57 \\
\hline
\end{tabular}

\subsection{Test Parameter}

Engine mass flow rates have an essential influence on the flow field upstream of the AIP. Therefore, in the experiments, realistic engine mass flow rates are reproduced with a fan, cf. Figure 1. The corrected mass flow rate is applied as defined in Equation (1), to achieve Mach numbers similar to flight conditions independent of flight altitude or weather [21].

$$
\dot{m}_{\text {corr }}=\dot{m} \cdot \sqrt{\frac{T_{t}}{T_{I S A}}} \frac{p_{I S A}}{p_{t, \infty}}
$$


Here, $T_{I S A}=288.15 \mathrm{~K}$ and $p_{I S A}=101,325 \mathrm{~Pa}$ are the ISA conditions at sea level. Ambient flight conditions are represented by the total temperature and total pressure measured at the wind tunnel nozzle exit, $T_{t}$ and $p_{t, \infty}$. Two coefficients are defined to evaluate the aerodynamic characteristics of the investigated intake shapes. The first is a normalized total pressure ratio $\bar{\eta}_{n o r m}$, based on Reference [2], to rate the efficiency of the ram compression, Equation (2). Total pressure ratios $\eta=p_{t} / p_{t, \infty}$ are normalized using the total pressure ratio $\eta_{\text {Ref }}$. For the reference value, the corrected mass flow rate 1 at zero freestream velocity is selected. (cf. Figure 8a). The AIP mean value $\bar{\eta}_{\text {norm }}$ is calculated of all 96 AIP measurement positions, cf. Figure 4a.

$$
\begin{aligned}
& \eta_{\text {norm }}=\frac{\eta}{\eta_{\text {Ref }}}, \quad \bar{\eta}_{\text {norm }}=\frac{1}{96} \sum_{i=1}^{96} \eta_{\text {norm }}, \\
& \eta_{\text {Ref }}=\eta\left(\text { Intake 1, no intake grid, } \frac{U_{\infty}}{U_{\infty, \text { max }}}=0, \frac{\dot{m}_{\text {corr }}}{\dot{m}_{\text {corr } \text { max }}}=0.79\right)
\end{aligned}
$$

The total pressure in a single measurement location is given by $p_{t}$, whereas $p_{t, \infty}$ is the total pressure at the wind tunnel nozzle exit. AIP total pressure distortion is an indicator for stable engine operation [22]. Therefore, the distortion coefficient $D C_{60}$ is employed to evaluate the non-uniformity of the total pressure distribution in the AIP. It gives the difference of the lowest average total pressure $p_{t, \text { low }}$ segment with an extent of $\theta=60 \mathrm{deg}$ and the AIP mean total pressure $p_{t, A I P}$ divided by the mean AIP dynamic pressure $q_{A I P}$. The parameter $D C_{60}=\left(p_{t, A I P}-p_{t, \text { low }}\right) / q_{A I P}$ is normalized using $D C_{60, R e f}$.

$$
\begin{aligned}
& D C_{60, \text { norm }}=\frac{D C_{60}}{D C_{60, \text { Ref }}}, \\
& D C_{60, \text { Ref }}=D C_{60}\left(\text { Intake 1, no intake grid, } \frac{U_{\infty}}{U_{\infty, \max }}=0, \frac{\dot{m}_{\text {corr }}}{\dot{m}_{\text {corr }, \text { max }}}=0.79\right)
\end{aligned}
$$

Figure 8a presents the mass flow rates which are investigated in the experiments. Here, mass flow rates 1-3 are due to different engine power requirements, whereas mass flow rate 4 is a constant maximum mass flow rate.

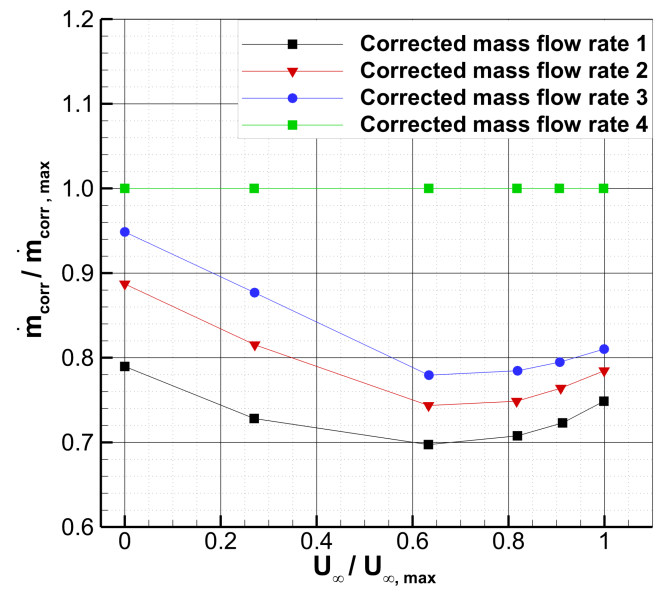

(a)

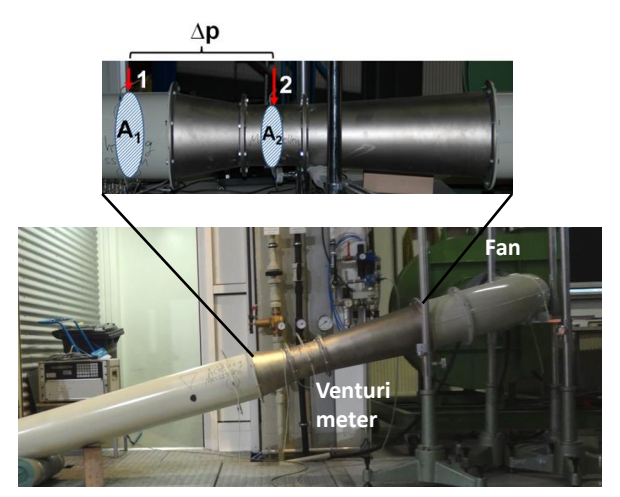

(b)

Figure 8. (a) Specified mass flow rate $\dot{m}_{c o r r} / \dot{m}_{c o r r, \text { max }}$ as function of the specified freestream velocity ratio $U_{\infty} / U_{\infty, \max } ;(\mathbf{b})$ venturi meter installation. 


\subsection{Five-Hole Pressure Probe Measurement}

For the AIP measurement of steady total pressures and the three velocity components, 5-hole pressure probes are employed. The distribution of the 5-hole probe measurement locations in the AIP is depicted in Figure 4a. The total of 96 measurement positions is achieved by measuring time-averaged pressure data at discrete circumferential positions using a 4-probe rake. The rake is positioned gradually at multiples of $\Delta \theta=15 \mathrm{deg}$. The AIP X-axis and the engine axis are collinear. The AIP Z-axis points at the middle of the intake opening. The AIP Y-axis generates a right-hand system with the AIP X-and Z-axes. AIP $\theta$ angles are defined as positive in clockwise direction. The calculation method for obtaining the three velocity components as well as the total pressure at all AIP measurement positions based on the five pressures of each 5-hole pressure probe is explained in [23]. The system's measurement accuracy is $\Delta p \approx \pm 0.001 p$. Here, $p$ is the pressure measured with a single 5-hole probe port.

\section{Intake Characteristics}

According to [2], helicopter intakes can be classified as pitot intakes, forward-facing side intakes (with plenum chamber) and sideways-facing side intakes (with plenum chamber). Due to its ram effect, with increased freestream Mach numbers, the pitot type intake delivers best recompression and thus efficieny $\eta$. The aerodynamic characteristics of plenum chamber type intake configurations are strongly dependent on their specific inner geometry. Sideways-facing intakes (static air intakes) deliver their maximum pressure recovery at a relatively low velocity in contrast to forward-facing intakes.

As part of [10] and [24], the aerodynamic characteristics of a dynamic pitot type and static sideways-facing air intake were experimentally tested in half-scale. It was found that the static side intake is mainly designed for low flight Mach numbers, for which $\eta$ is higher compared to the dynamic intake, Figure 9a. The $D C_{60}$ levels are lower for the side intake in slow flight and considerably higher in fast forward flight [10].

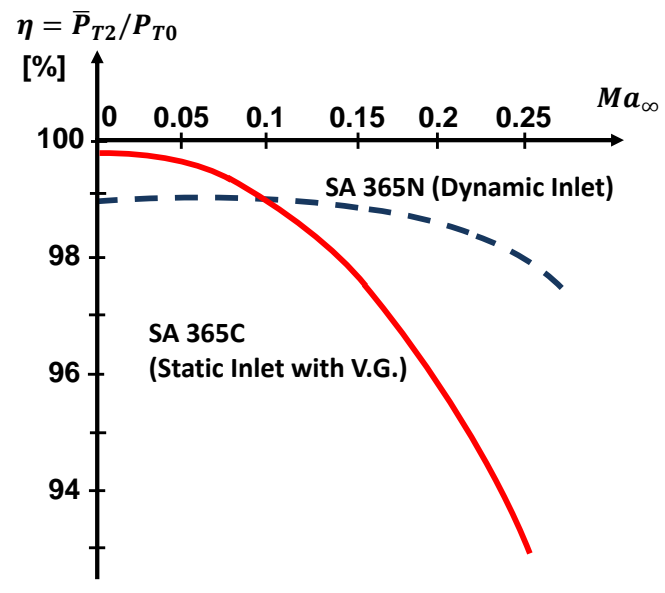

(a)

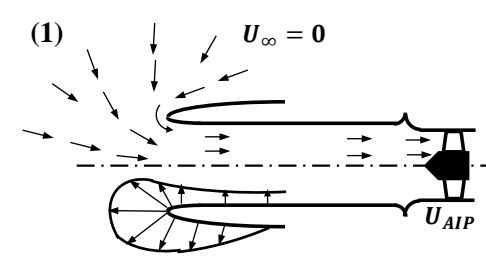

(2) $U_{\infty}=0$
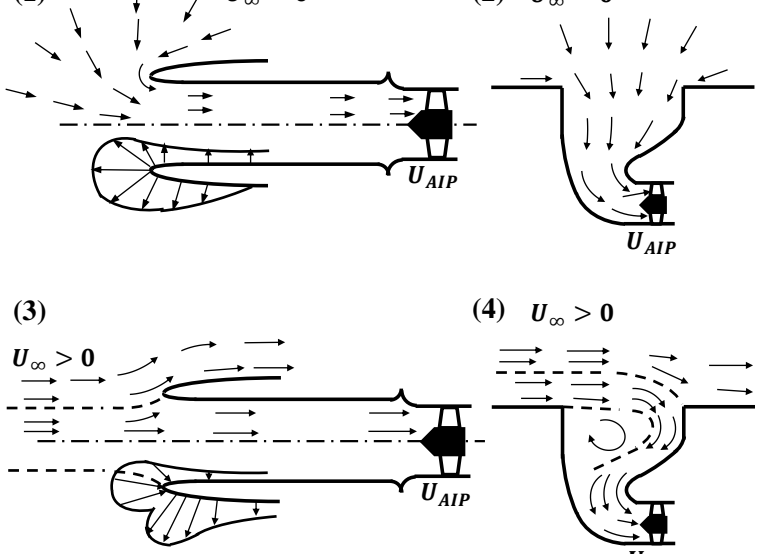

(4) $U_{\infty}>0$

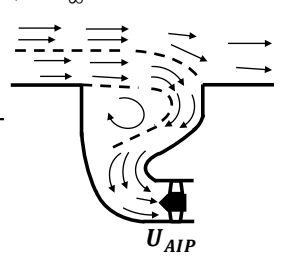

(b)

Figure 9. (a) Air intake efficiency, wind tunnel tests, based on [24]; (b) schematic of intake flow field (1) dynamic intake at $U_{\infty}=0 \mathrm{~m} / \mathrm{s},(2)$ static intake at $U_{\infty}=0 \mathrm{~m} / \mathrm{s}$, (3) dynamic intake at $U_{\infty}>0 \mathrm{~m} / \mathrm{s}$,

(4) static intake at $U_{\infty}>0 \mathrm{~m} / \mathrm{s}$, based on [10].

This is due to the fact that in hover flight air is ingested from all sides and is deflected less around the intake lips in case of the static side intake, Figure 9b(1),(2). In Figure 9b(3),(4) flow directions are schematically presented for fast forward flight. The high DC60 and low $\eta$ levels of the side intake are a consequence of the strong deflection around the front intake lip, which creates a region of separated flow (Figure 9b(4)). 


\section{Results and Discussions}

\subsection{AIP Coefficients, Retrofit Modifications}

In the following, main influences of rear spoilers with variable heights and lengths as well as an intake guide vane at three different streamwise positions are investigated as retrofit modifications for the baseline configuration. Therefore, Figures 10 and 11 refer to the effect on $\bar{\eta}_{\text {norm }}$ and $D C_{60, \text { norm }}$ in dependence of freestream velocity. The variation of mass flow rates has a minor effect on the coefficients comparing to freestream velocities and is not regarded in the current research. The corresponding relative overlapping parameter $\mathrm{R}$, height parameter $H_{r e l}$ as well as the parameter that describes the intake guide vane's positioning $P_{I G V}$ are given in Table 2. As depicted for the maximum mass flow rate in Figure 10a, in terms of total pressure losses, the short variants of the rear spoiler $(R=0.29)$ are beneficial for the low velocity conditions and the high variants $\left(1.91<H_{r e l}<2.19\right)$ are better suitable for the fast forward flight conditions. The additional total pressure losses in the low velocity regime are caused by a stronger flow deflection for the portion of the mass flow that is ingested from the back side of the intake. Regions of separated flow are created on the inside of the rear spoiler for low velocities. Therefore, covering of the intake opening (increasing $R$ ) deteriorates $\bar{\eta}_{\text {norm }}$. In fast forward flight conditions, the ram effect is increased with an increase in rear spoiler height and higher $\bar{\eta}_{\text {norm }}$ levels are achieved. In general, the high and short rear spoiler is the best combination of the $R$ and $H_{\text {rel }}$ variation that covers all flight conditions with acceptable pressure losses. In [10], additional intake total pressure losses of $1 \%$ are estimated to create a decrease of engine power output of $\geq 2 \%$. Thus, for the short and high rear spoiler version, a reasonable engine power increase of $0.6 \%$ can be estimated in fast forward flight while in slow flight, a decrease of $0.3 \%$ is assessed. Based on the high and short rear spoiler configuration (RSP3 IGV0), an intake guide vane at three different positions $P_{I G V}$ is investigated, cf. Figure 10b. Here, "IGV1, 2 and 3" refer to the front, middle and back positioning, respectively. In terms of $\bar{\eta}_{\text {norm }}$, the additional AIP total pressure in fast forward flight due to the improved flow deflection around the front intake lip is small for all three positions compared to the "pure" rear spoiler configuration. As an effect of the increased blockage of the intake opening, the intake guide vanes significantly reduce $\bar{\eta}_{\text {norm }}$ for $U_{\infty} / U_{\infty, \max } \rightarrow 0$, see Figure $10 \mathrm{~b}$.

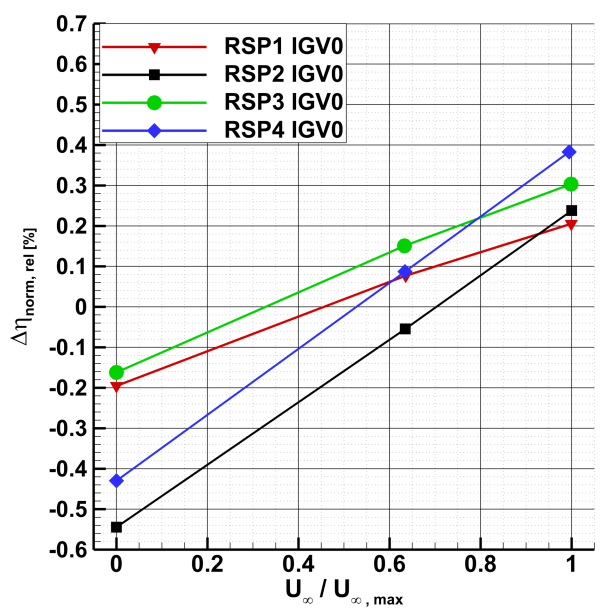

(a)

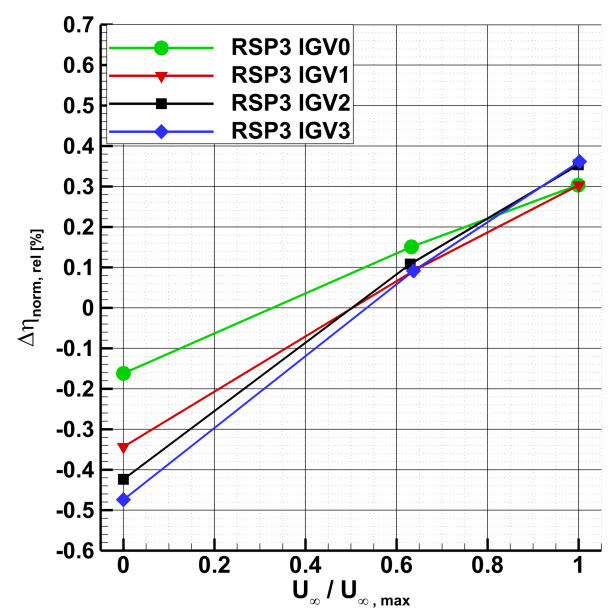

(b)

Figure 10. Relative $\bar{\eta}_{\text {norm }}$ difference compared to baseline configuration in dependence of freestream velocity ratio, for $\dot{m}_{c o r r} / \dot{m}_{c o r r, \max }=1$ (a) retrofit rear spoilers; (b) retrofit rear spoilers with intake guide vane. 
Regarding $D C_{60, \text { norm }}$ in Figure 11a, all rear spoiler variants reveal a higher level than the baseline configuration without rear spoiler for low $U_{\infty} / U_{\infty, \max }$.

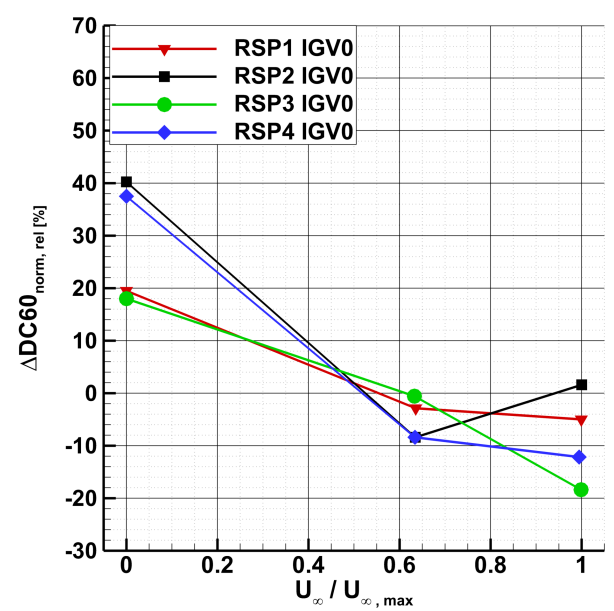

(a)

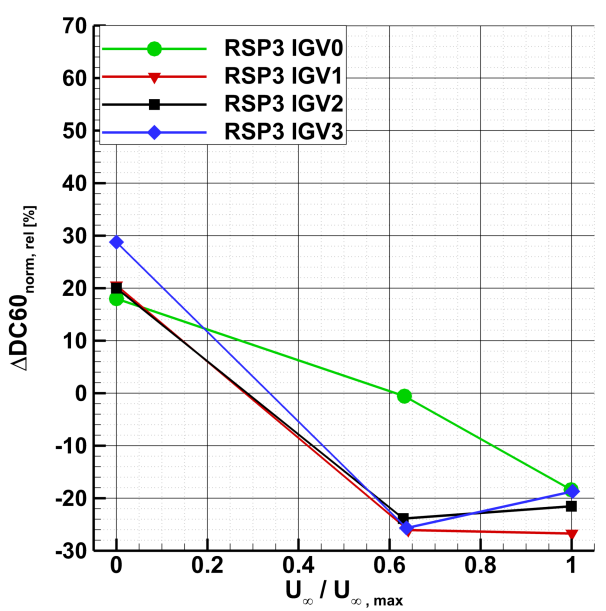

(b)

Figure 11. Relative difference in $D C_{60, n o r m}$ compared to baseline configuration in dependence of freestream velocity ratio, for $\dot{m}_{\text {corr }} / \dot{m}_{\text {corr,max }}=1$ (a) retrofit rear spoilers; (b) retrofit rear spoilers with intake guide vane.

On the contrary, the rear spoilers, especially the high versions, reduce the total pressure distortion in the AIP at high $U_{\infty} / U_{\infty, \max }$. Also with respect to the total pressure distortion, a short rear spoiler is beneficial in the low velocity regime. Referring to Figure 11b, the installation of the guide vane leads to an increase of the $D C_{60, \text { norm }}$ coefficient at low freestream velocity. The total pressure distortion is significantly reduced by the guide vanes in the medium and high velocity regime. In summary, the intake guide vane in its front position combined with the high and short rear spoiler provides the lowest levels of total pressure distortion. As part of the research performed in [25], engine power output in dependence of $D C_{60}$ levels was measured for a Turbomeca Turmo IVB gas turbine. From the corresponding data, for a starting level of $D C_{60} \approx 0.05$ a relative reduction of $\Delta D C_{60} \approx 20 \%$ leads to an increase in engine power of $\approx 0.45 \%$. For a starting level of $D C_{60} \approx 0.1$ an increase in engine power of $\approx 0.22 \%$ can be assumed. Thus, the power output improvement due to decreased distortion in fast forward flight are of the same order as those which are attributed to improved total pressure levels. In Figure 12, the progression of the $\bar{\eta}_{\text {norm }}$ and $D C_{60 \text {, norm }}$ characteristics in dependence of freestream velocities of the baseline configuration and the best retrofit modifications (RSP3 IGV0, RSP3 IGV1) is presented. Both figures indicate a very similar trend as has been found in [10] for side intake configurations. Total pressure losses $(1-\bar{\eta})$ are nearly proportional to $U_{\infty}^{2}$. Especially for the baseline configuration, an increase in total pressure distortion can be observed with increase in freestream velocity. 


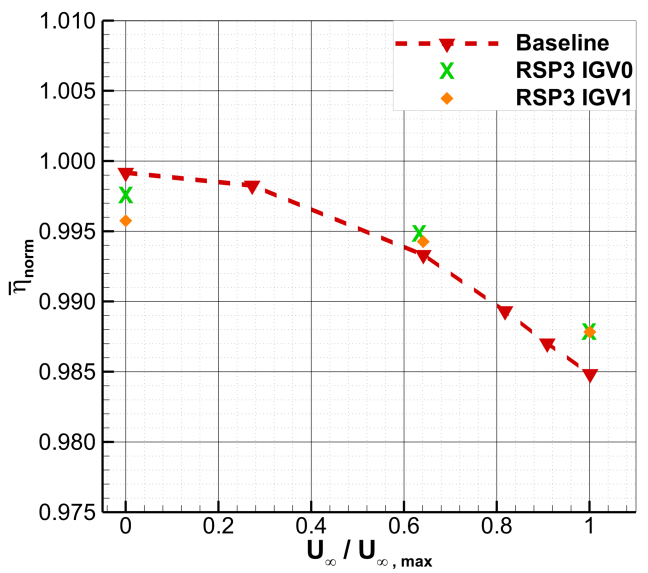

(a)

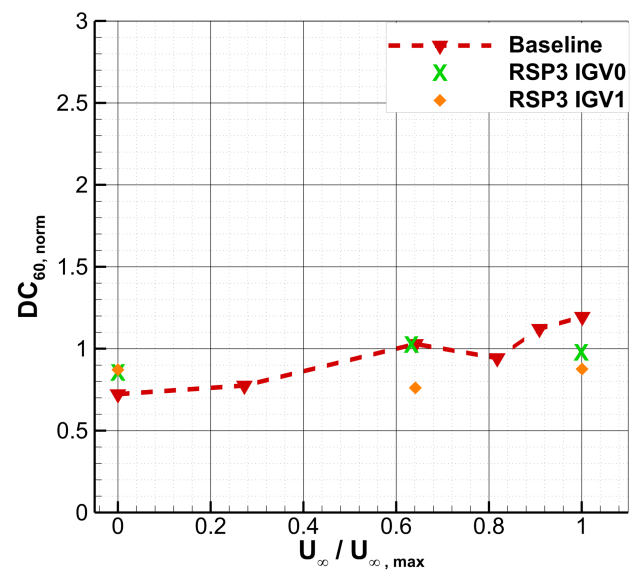

(b)

Figure 12. AIP coefficient progression of baseline configuration and best retrofit variants for $\dot{m}_{\text {corr }} / \dot{m}_{\text {corr }, \text { max }}=1$ (a) normalized total pressure ratio; (b) normalized distortion coefficient.

\subsection{AIP Detail Investigation of Best Retrofit Modifications}

Further investigations of $\eta_{\text {norm }}$ AIP distributions corresponding to the $\bar{\eta}_{\text {norm }}$ and $D C_{60, \text { norm }}$ trends of Figure 12 are presented. The baseline configuration (Intake 2 and Plenum 3) serves as the reference for the optimization and as geometrical basis for the retrofit modifications. As a consequence, the corresponding data is compared to those of the two best retrofit versions. For this purpose, two combinations of operation conditions of $U_{\infty} / U_{\infty, \max }$ and $\dot{m}_{c o r r} / \dot{m}_{c o r r, \max }$ are selected for which the largest differences in $\bar{\eta}_{\text {norm }}$ and $D C_{60, \text { norm }}$ occur. The first operation condition is $U_{\infty} / U_{\infty, \max }=0$, $\dot{m}_{\text {corr }} / \dot{m}_{\text {corr, } \max }=1$. The $\eta_{\text {norm }}$ distribution clearly reflects the trend of Figure 12a. For low freestream velocities air is ingested into the intake entry from all sides. The completely uncovered baseline intake is therefore advantageous compared to the partly covered configurations including a rear spoiler and intake guide vane. These elements promote local flow separation for $U_{\infty} / U_{\infty, \max } \rightarrow 0$. Thus, the AIP area of high $\eta_{n o r m}$ values as well as the overall level increase in the order of (c), (b) and (a), as depicted in Figure 13. Generally, $\eta_{\text {norm }}$ is low in the area of the AIP between 90 deg $<\theta<270$ deg. The air which enters the EID in the corresponding sector has passed through very turbulent regions of the flow field in the upstream situated plenum chamber. Therefore, its total pressure is decreased. Strong deviation from a radial inflow direction at the EID entry results in separations at the EID inner and outer guide vanes (cp. Figure 4) fostering further total pressure losses. In the top AIP region, the highest $\eta_{\text {norm }}$ levels are noticeable due to the fact that air from the rather undisturbed freestream flow is particularly ingested here and enters the EID in the radial direction (Reference also [14]). 


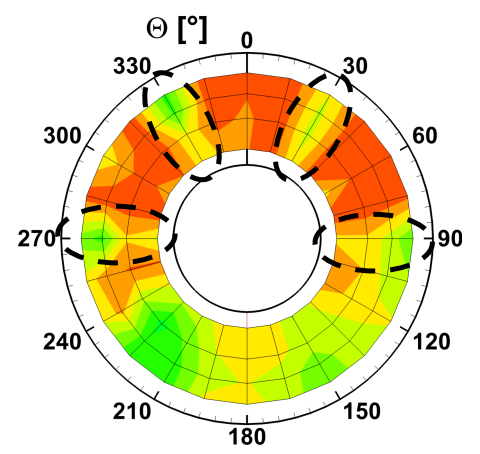

(a)

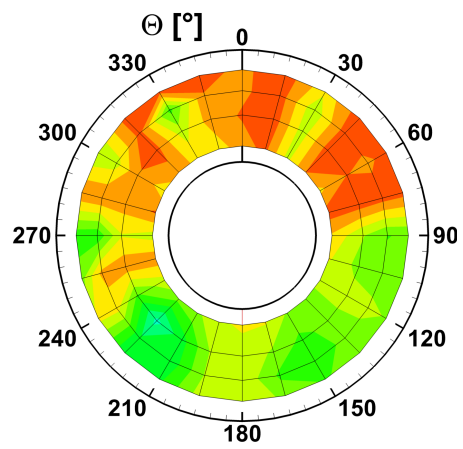

(b)

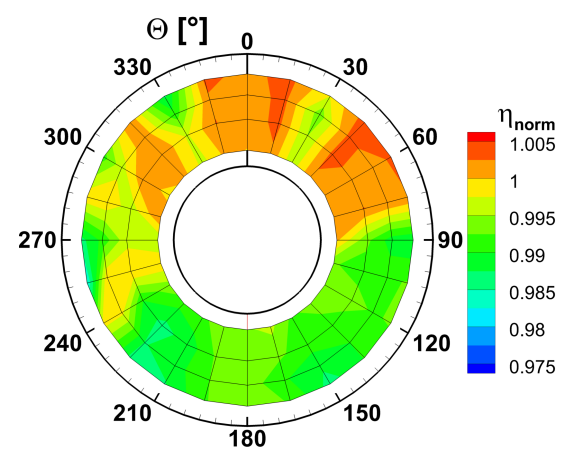

(c)

Figure 13. Distribution of $\eta_{\text {norm }}$ in AIP for (a) baseline configuration; (b) RSP3 IGV0; (c) RSP3 IGV1, $U_{\infty} / U_{\infty, \max }=0, \dot{m}_{\text {corr }} / \dot{m}_{\text {corr }, \max }=1$.

The regions corresponding to highest losses are located very similarly for the three configurations. The small differences in $D C_{60, \text { norm }}$ (cp. Figure 12b) are not clearly identifiable from the $\eta_{\text {norm }}$ AIP distributions. Especially in the upper AIP region, characterized by overall high dynamic pressures, wakes of the EID guide vanes are visible for $\theta=30 \mathrm{deg}, 90 \mathrm{deg}, 270 \mathrm{deg}$ and $330 \mathrm{deg}$. The corresponding $\eta_{\text {norm }}$ deficits are shown exemplarily in Figure 13 and marked with black dashed circles. The fact that the wakes are not transported in circumferential direction shows that in this regime the radial direction is the prevailing inflow direction at the EID entry.

The second operation point is characterized by $U_{\infty} / U_{\infty, \max }=1, \dot{m}_{\text {corr }} / \dot{m}_{\text {corr, } \max }=1$. The trend is reversed for this operation point. The area of low $\eta_{\text {norm }}$ in the regime of $90 \mathrm{deg}<\theta<270 \mathrm{deg}$ is clearly reduced due to the rear spoiler compared to the baseline intake, as depicted in Figure 14a,b.

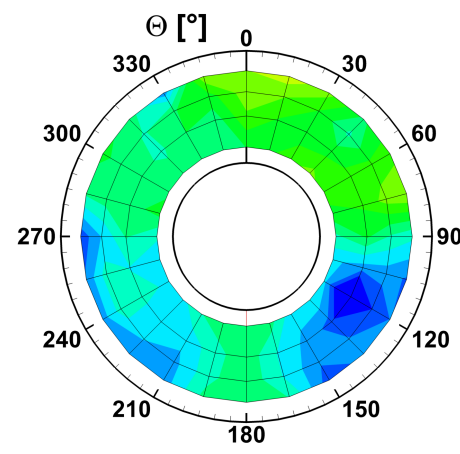

(a)

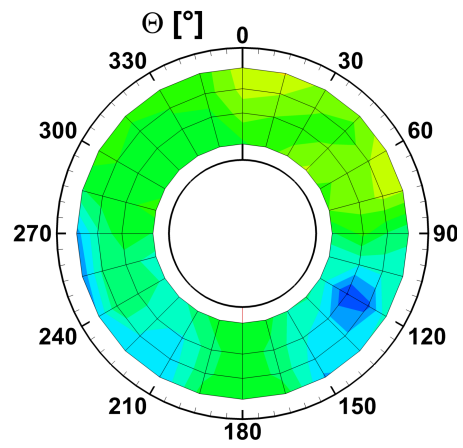

(b)

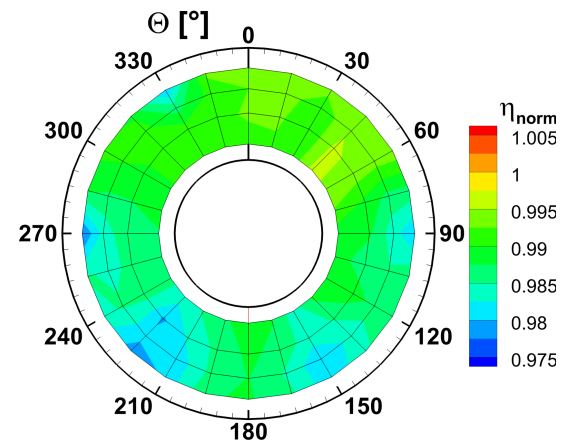

(c)

Figure 14. Distribution of $\eta_{\text {norm }}$ in AIP for (a) baseline configuration; (b) RSP3 IGV0; (c) RSP3 IGV1, $U_{\infty} / U_{\infty, \max }=1, \dot{m}_{\text {corr }} / \dot{m}_{\text {corr }, \max }=1$.

The intake guide vane leads to a different distribution with even higher $\eta_{\text {norm }}$ levels in this area. The location of the region of decreased $\eta_{\text {norm }}$ in between $200 \mathrm{deg}<\theta<280 \mathrm{deg}$ is similar for all three configurations, with the lowest level of $\eta_{n o r m}$ for the baseline intake. Overall, the trend of the $\bar{\eta}_{\text {norm }}$ coefficient of Figure 12a is confirmed. The very homogeneous $\eta_{\text {norm }}$ distributions for the two retrofit variants clearly reflect the decreased distortion levels in comparison to the baseline intake version, compare Figure 12b. Due to the total pressure distortion, both a reduction of the engine's power output (cf. [25]) and a decrease of engine stability due to a loss of surge margin is imposed. Circumferential total pressure variations have a considerably higher influence on the loss of surge margin of the compressor than radial total pressure deficiencies, referring to [26]. Highest surge margin loss is caused by low total pressure sectors with an extent angle of $60 \mathrm{deg}-90 \mathrm{deg}$, according to [26]. 
Of the geometries comprised in this study, an angle close to that extent appeared only for the Intake 2 in fast forward flight conditions $\left(U_{\infty} / U_{\infty, \max }=1\right)$. In this operation condition, the margin from the surge line to the stationary operation line is larger than in hover condition. Thus, engine power loss due to distortion is more important than its detrimental effect on engine stability.

\subsection{Static Pressure Measurements}

In the wind tunnel experiment, static surface pressures are measured at 192 positions. The measurement accuracy of the system is $c_{p} \approx \pm 0.01$. For the definition of $c_{p}$, the dynamic pressure $q_{\infty}=0.5 \times \rho_{\infty} \times U_{\infty}^{2}$ is acquired with a Prandtl probe at the wind tunnel nozzle exit. Pressure taps are located in 8 lines along the surface of the outer geometry, as depicted in Figure 15a. For a clear distinction, the intake lips are labeled. Further pressure taps are situated on 9 lines along the surface of the inner parts of the geometry, see Figure 16a. Line 9 is located in the mid-plane of the engine plenum chamber.

A local curve length coordinate $S$ is defined for each line. The coordinate $S$ ranges from 0 to 1 and its orientation is along the surface in mainstream direction. Subsequently, the front intake lip pressure distributions of Line 2 are analyzed for the baseline intake in comparison to the best two retrofit variants, RSP3 + IGV0 and RSP3 + IGV1, Figure 15b. The longitudinal section through the model at Line 2 is also illustrated (red line), together with the corresponding coordinate $S$ for the surface pressure tap locations (green dots). The fast forward flight operation condition $\left(U_{\infty, \max }, \dot{m}_{c o r r, \max }\right)$ is regarded. Directly at and downstream of the front intake lip, at the location $S_{2}=0.92-0.96$, the high and short rear spoiler (RSP3) increases the pressure level comparing to the baseline intake variant by $\Delta c_{P, R S P} \approx 0.16$, as illustrated in Figure $15 \mathrm{~b}$. The retrofit variant including the intake guide vane leads to a pressure gain of $\Delta c_{P} \approx 0.27$ indicating a less pronounced separation region at the front intake lip.

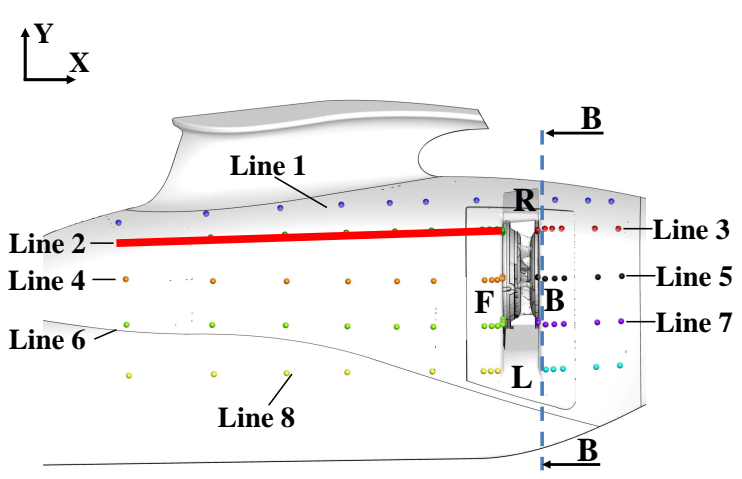

(a)

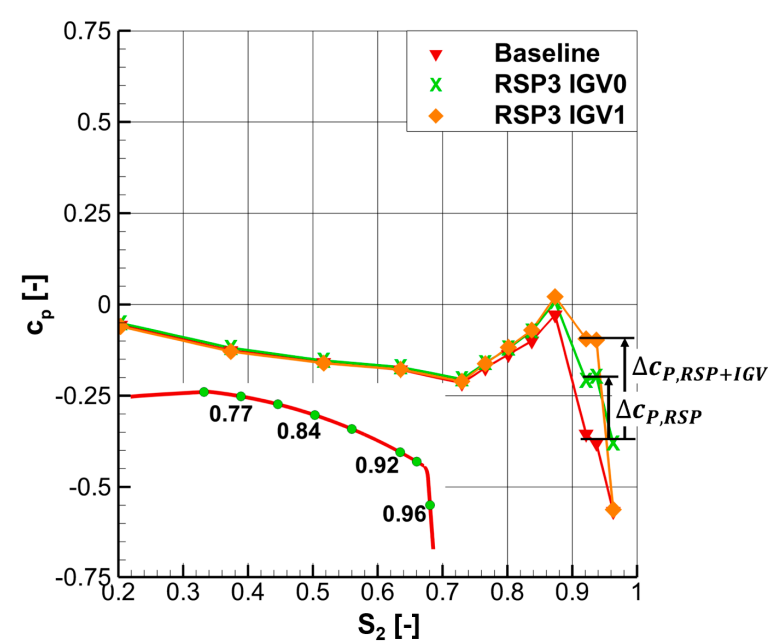

(b)

Figure 15. (a) Pressure tap positions on the outer geometry of Intake 1, red line indicating Line 2; (b) pressure distributions at Line 2, baseline and best retrofit variants, $U_{\infty} / U_{\infty, \max }=1$, $\dot{m}_{\text {corr }} / \dot{m}_{\text {corr }, \max }=1$. 


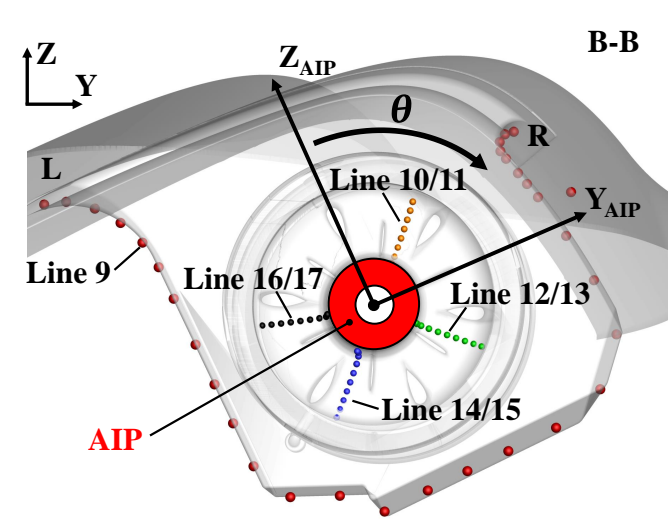

(a)

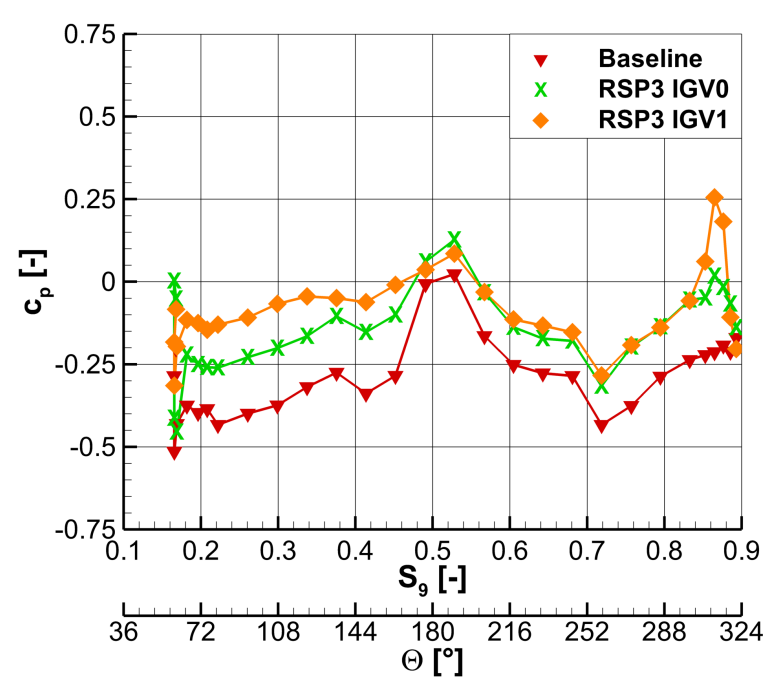

(b)

Figure 16. (a) Cut view B-B in $Y_{A I P}-Z_{A I P}$ plane, exemplary pressure tap positions on the inner geometry of Plenum 1; (b) pressure distributions at Line 9, baseline and best retrofit variants, $U_{\infty} / U_{\infty, \max }=1, \dot{m}_{\text {corr }} / \dot{m}_{\text {corr }, \max }=1$.

As shown in Figure 16b, the pressure distributions imply a very complex plenum chamber flow field. Comparing all intake variants, pressure differences in the plenum chamber are similar to the entry cross section of the intake. Thus, the static pressure at the intake entry is crucial for downstream plenum chamber pressure levels.

The retrofit modifications lead to an increase of static pressure over the entire plenum chamber, compared to the baseline configuration. In the region around $S_{9}=0.49-0.53$, a pressure increase due to the plenum splitter is clearly visible for all configurations. The increase of surface pressures at the intake entry due to the guide vane compared to the "pure" rear spoiler is not entirely reproduced over the complete plenum chamber. This indicates differences in the local effectiveness of such a device interacting with a rear spoiler or scoop. For all intake geometries, the flow is accelerated around the right side intake lip at $\theta \approx 60 \mathrm{deg}$ leading to a decrease of static pressure. The EID pressure distributions are not presented here as they mainly indicate a strong area contraction from EID entry to exit (AIP) and thus a pronounced pressure drop [13]. The strong acceleration in main flow direction results in very low swirl angles close to zero in the AIP. For that reason only little power loss is expected due to swirl-induced local compressor blade incidence angles.

\section{Conclusions}

Based on selected experimental results, achieved with a new full-scale wind tunnel model of a helicopter fuselage section, aerodynamic characteristics of helicopter side air intakes are investigated. Helicopter engine operation conditions are simulated in the experiment by adjusting corrected mass flow rates. Circumferentially adjustable 5-hole pressure probes are applied to analyze total pressures and the three velocity components in the aerodynamic interface plane. Surface pressure distributions give further insight into local flow phenomena. In previous investigations, the effect of three basic engine intake and plenum chamber shapes on a normalized total pressure ratio and normalized total pressure distortion coefficient were investigated. In the current study, retrofit modifications, fitted to a semi-dynamic intake configuration, are investigated. These are meant to combine the different beneficial operating conditions of the static, semi-dynamic and dynamic basic geometries. The investigations of retrofit modifications applied to the semi-dynamic baseline configuration include rear spoilers with different heights and lengths as well as an intake guide vane at three different streamwise positions. Two geometric variants are chosen as the optimal retrofit modifications. The high 
rear spoilers are assessed best for fast forward flight due to best static pressure recompression upstream of the intake entry section. The short ones are rated as most beneficial for slow freestream velocities due to less flow deflection of the ingested air. Thus, the high and short rear spoiler is evaluated as the best rear spoiler configuration. In fast forward flight an improvement of $0.3 \%$ in engine entry total pressure and a decrease of total pressure distortion of nearly $20 \%$ lead to a considerable increase in engine power. In helicopter mission envelopes, in terms of the emissions, the most relevant flight condition is fast forward flight. Therefore, with reasonable effort, a noticeable emission reduction can be achieved due to the retrofit modification. The investigation of an additional intake guide vane unveils best total pressure and total pressure distortion results in its front position. Nevertheless, the additional total pressure gain due to the guide vane for high freestream velocities is small compared to the "pure" rear spoiler configuration even if the pressure distributions indicate an improved flow deflection around the front intake lip. In the mid and high freestream velocity regime, a significant additional total pressure distortion decrease of $10 \%-20 \%$ can be related to the intake guide vane. The plenum chamber pressure distributions indicate differences of the local effectiveness of such a device interacting with a rear spoiler or scoop. The application of a twisted, variably cambered or slotted intake guide vane could markedly help to improve low loss flow deflection around the intake lip of such sideways-facing side air intakes. As an effect of the increased blockage of the intake opening, the intake guide vanes significantly reduce total pressures for the low speed test points. Both best retrofit variants show $20 \%$ higher total pressure distortion levels than the semi-dynamic version for the low velocity regime. The static pressure distributions substantiate the importance of an increase of static intake entry pressure on AIP total pressure levels. This reassures the effectiveness of external retrofit modifications. Two main flow regions are unveiled in the aerodynamic interface plane total pressure distributions for the intake geometries. The lower AIP part is dominated by low total pressures. Regions of strong mixing and flow separation in the upstream plenum chamber are the reason for total pressure losses in the corresponding angular regime. The highest total pressure levels occur in the AIP top part, where predominantly air from the undisturbed freestream flow is ingested. In the lower part, an increase of total pressure levels can be realized using retrofit modifications for fast forward flight conditions. The more homogeneous total pressure distributions substantiate a significant decrease in total pressure distortion. The previous investigations and testing procedures can be used for a detailed investigation of the inner flow field in other novel helicopter intakes which is a valuable investigation in the early design phase of the engine-airframe integration process. A detailed assessment of the distortion's influence on surge margins as well as engine power gains through distortion reduction and total pressure increase is only possible in combination with the specific compressor performance map and compressor geometry. The latter information is further essential for the evaluation of drag penalties or gains in relation to power benefits for such intake configurations related to a global helicopter efficiency consideration.

Acknowledgments: The work presented in this paper is based on the investigation of the ATHENAI (Aerodynamic Testing of Helicopter Novel Air Intakes) project. The ATHENAI project belonged to the Green Rotorcraft 2 (GRC2) sub-project within the Clean Sky JTI (Joint Technology Initiative). The research project ATHENAI was funded within the European Commission's Seventh Framework Program (FP/2007-2013) for the Clean Sky Joint Technology Initiative under grant agreement number 619819. The authors would like to thank the project partner Airbus Helicopters Deutschland $\mathrm{GmbH}$ for the support and the successful cooperation.

Author Contributions: Florian Knoth and Christian Breitsamter designed the experiments. Florian Knoth performed the experiments and analyzed the data. Florian Knoth and Christian Breitsamter wrote the paper.

Conflicts of Interest: The authors declare no conflict of interest. 


\section{Abbreviations}

The following abbreviations are used in this manuscript:

$\begin{array}{ll}\text { AIP } & \text { Aerodynamik interface plane } \\ \text { ATHENAI } & \text { Aerodynamik Testing of Helicopter Novel Air Intakes } \\ \text { DC60 } & \begin{array}{l}\text { Distortion coefficient, lowest total pressure } 60 \text { deg sector in AIP } \\ \text { less mean AIP total pressure, divided by AIP mean dynamic head }\end{array} \\ \text { TUM-AER } & \text { Chair of Aerodynamics and Fluid Mechanics of the Technical University of Munich } \\ \text { EID } & \text { Engine intake duct } \\ \text { EPC } & \text { Engine plenum chamber } \\ \text { IGV } & \text { intake guide vane, retrofit modification } \\ \text { RSP } & \text { Rear spoiler, retrofit modification } \\ \text { ISA } & \text { International standard atmosphere } \\ \text { W/T } & \text { Wind tunnel }\end{array}$

\section{References}

1. Grawunder, M.; Ress, R.; Breitsamter, C.; Adams, N.A. Flow characteristics of a helicopter fuselage configuration including a rotating rotor head. In Proceedings of the 28th Congress of the International Council of the Aeronautical Sciences, Brisbane, Australia, 23-28 September 2012; pp. 1-14.

2. Seddon, J.; Goldsmith, E.L. Intake Aerodynamics, 1st ed.; Collins Professional and Technical Books: London, UK, 1985.

3. Bissinger, N.C.; Breuer, T. Basic principles-Gas turbine compatibility-Intake aerodynamic aspects. In Encyclopedia of Aerospace Engineering, 1st ed.; Wiley: New York, NY, USA, 2010; Volume 8, pp. 2-5, doi:10.1002/9780470686652.eae487.

4. Laruelle, G. AIR intakes: Role, constraints and design. In Proceedings of the 23th Congress of the International Council of the Aeronautical Sciences, Toronto, ON, Canada, 8-13 September 2002; pp. 1-16.

5. Sóbester, A. Tradeoffs in jet inlet design: A historical perspective. J. Aircr. 2007, 44, 705-717.

6. Heise, R.; Meyer, C.J.; von Backström, T.W. Evaluation of helicopter intakes in the presence of a rotor. In Proceedings of the 32th European Rotorcraft Forum, Maastricht, The Netherlands, 12-14 September 2006.

7. Bojdo, N.; Filippone, A. Performance prediction of inlet barrier filter systems. J. Aircr. 2011, 48, $1903-1912$.

8. Bojdo, N.; Filippone, A. Comparative study of helicopter engine particle separators. J. Aircr. 2014, 51, 1030-1042.

9. Pagnano, G.; Ballard, J. Development and testing of the a129 air intake. In Proceedings of the Ninth European Rotorcraft Forum, Stresa, Italy, 13-15 September 1983.

10. Vuillet, A. Aerodynamic design of engine air intakes for improved performance. In Proceedings of the Sixth European Rotorcraft and Powered Lift Aircraft Forum, Bristol, UK, 16-19 September 1980.

11. Ahn, G.B.; Jung, K.Y.; Myong, R.S. Numerical and experimental investigation of ice accretion on rotorcraft engine air intake. J. Aircr. 2015, 52, 903-909.

12. de Bruin, A.C.; Fatigati, G.; Shin, H.B. Kai surion helicopter full-scale air intake testing at CIRA icing wind tunnel. In Proceedings of the 30th Congress of the International Council of the Aeronautical Sciences, Daejeon, Korea, 25-30 September 2016.

13. Knoth, F.; Breitsamter, C. Aerodynamic characteristics of helicopter engine side air intakes. Aircr. Eng. Aerosp. Technol. 2017, under review.

14. Knoth, F.; Breitsamter, C. Flow analysis of a helicopter engine side air intake. J. Propuls. Power 2017, 0, 1-15.

15. Bebesel, M.; D'Alascio, A.; Schneider, S.; Guenther, S.; Vogel, F.; Wehle, C.; Schimke, D. Bluecopter demonstrator-An approach to eco-efficient helicopter design. In Proceedings of the 41st European Rotorcraft Forum, Munich, Germany, 1-4 September 2015.

16. Knoth, F.; Breitsamter, C. Aerodynamic testing of helicopter novel air intakes. In Proceedings of the 30th Congress of the International Council of the Aeronautical Sciences, Daejon, Korea, 25-30 September 2016; pp. 1-13.

17. Fassl, F.; You, J.H.; Breitsamter, C. Wirkscheibenmodellierung des hubschrauber-hauptrotors hinsichtlich des einflusses auf den fenestronlärm. Semester Thesis, Chair of Aerodynamics and Fluid Mechanics, Technische Universität München: Munich, Germany, 2015. 
18. Rae, W.H.; Pope, A. Low-Speed Wind Tunnel Testing, 2nd ed.; Wiley: Hoboken, NJ, USA, 1984.

19. Vogel, F. Aerodynamische analysen an helikopter zellen-ausleger konfigurationen. dissertation, Technische Universität München: Munich, Germany, 2016.

20. Liao, C.C.; Liou, T.L. Flows in a curved combustor inlet with and without a guide vane. J. Propuls. Power 1995, 11, 464-472.

21. Bräunling, W.J.G. Flugzeugtriebwerke, 3rd ed.; Springer: Berlin/Heidelberg, Germany, 2009.

22. Braithwaite, W.M.; Soedert, R.H. Combined pressure and temperature distortion effects. J. Aircr. 1980, $17,468-472$.

23. Johansen, E.S.; Rediniotis, O.K.; Jones, G. The compressible calibration of miniature multi-hole probes. J. Fluids Eng. 2001, 123, 128-138.

24. Roesch, P. Aerodynamic design of the aerospatiale SA $365 \mathrm{~N}$ dauphin 2 helicopter. In Proceedings of the Sixth European Rotorcraft and Powered Lift Aircraft Forum, Bristol, UK, 16-19 September 1980.

25. Van der Walt, J.P.; Nurick, A. Static pressure distribution in the inlet of a helicopter turbine compressor. J. Aircr. 1994, 31, 1411-1413.

26. Reid, C. The Response of Axial Flow Compressors to Intake Flow Distortion; ASME 1969 Gas Turbine Conference and Products Show: Cleveland, OH, USA, 1969.

(C) 2017 by the authors. Licensee MDPI, Basel, Switzerland. This article is an open access article distributed under the terms and conditions of the Creative Commons Attribution (CC BY) license (http://creativecommons.org/licenses/by/4.0/). 